\title{
Influência do sortimento de toras na produtividade de um carregador florestal
}

\author{
Carlos Cezar Cavassin Diniz ${ }^{*}$, Clebson Lima Cerqueira ${ }^{1}$, Felipe Martins de Oliveira²
}

\begin{abstract}
RESUMO: Objetivou-se analisar a influência do sortimento de toras na operação de carregamento florestal. Os dados foram coletados em áreas de colheita florestal de Pinus taeda de uma empresa florestal localizada no estado do Paraná, Brasil. A análise técnica abordou um estudo de tempos e movimentos. Calculou-se o número de garradas, tempo de carregamento e produtividade para cada tratamento (I, II, III e IV), posteriormente, realizou-se uma análise estatística por meio da ANOVA, bem como o teste de Tukey ( $\mathrm{p}_{\text {valor }}<0,05$ ). Os resultados mostraram que a eficiência operacional obtida foi de $59,7 \%$ sendo afetada principalmente pela espera dos veículos de transporte para o carregamento. $\mathrm{O}$ tratamento I apresentou o maior número de garradas para completar a carga, aumentando em 44,8\% em relação ao tratamento II. Os menores tempos obtidos para completar a carga do veículo de transporte foram obtidos nos tratamentos II e III respectivamente, explicado pelo comprimento das toras presentes nesses tratamentos. Em relação a produtividade da operação de carregamento, novamente os tratamentos II e III mostraram superioridade, com diferença estatística pelo teste de Tukey (pvalor $<0,05$ ). Tais resultados denotam que os diferentes sortimentos estudados apresentam influência sobre a operação de carregamento de madeira.
\end{abstract}

Palavras-chave: Carregamento de madeira, rendimento, análise técnica.

\section{Influence of assortments of logs in the productivity of a forest loader}

\begin{abstract}
The objective of this work was to analyze the influence of the assortment of logs in the forest loading operation. The data were collected in forest harvesting areas of Pinus taeda from a forest company located in Paraná state, Brazil. The technical analysis addressed a study of times and movements. The number of gills, loading time and productivity for each treatment (I, II, III and IV) were calculated, and a statistical analysis was performed using ANOVA, as well as the Tukey test $\left(\mathrm{p}_{\text {valor }}<0.05\right.$ ). The results showed that the operational efficiency obtained was $59.7 \%$ and was affected mainly by waiting the transport vehicles for loading. Treatment $I$ had the highest number of claws to complete the load, increasing by $44.8 \%$ in relation to treatment II. The smaller times obtained to complete the load of the transport vehicle were obtained in the treatments II and III respectively, explained by the length of the logs present in these treatments. Regarding the productivity of the loading operation, treatments II and III again showed superiority, with statistical difference by the Tukey test $\left(\mathrm{p}_{\text {valor }}<0.05\right)$. These results indicate that the different assortments studied have influence on the wood loading operation.
\end{abstract}

Keywords: Loading wood, yield, technical analysis.

\section{INTRODUÇÃO}

Devido a abertura do mercado brasileiro para importações em 1990, empresas de base florestal passaram a adquirir máquinas com elevada tecnologia em comparação com as máquinas até então utilizadas. Apesar de anos após essa abertura no mercado, a mecanização da atividade de colheita e transporte florestal ainda passa por momentos de grandes inovações e avanços tecnológicos, onde as montadoras procuram aliar tecnologia, precisão e robustez em suas máquinas (NASCIMENTO et al., 2011).

Dentre as atividades do ciclo produtivo de uma floresta plantada, pode-se destacar duas atividades chave, dada a representação das mesmas no custo final da floresta. Chegando a representar $60 \%$ dos custos de produção de uma floresta, as atividades de colheita e transporte florestal são atividades chave. A colheita florestal representa a operação final de um ciclo de produção florestal, na qual são obtidos os produtos mais valiosos, constituindo um dos fatores que determinam a rentabilidade florestal (ARCE et al., 2004).

De acordo com Machado (2014), nas operações de colheita florestal, o melhor desempenho depende diretamente do conhecimento do volume da floresta, das condições locais, do planejamento criterioso das operações de corte, extração, carregamento, transporte e descarregamento.

O carregamento refere-se à operação em que a madeira é colocada no veículo de transporte, sendo o

\footnotetext{
Recebido em 19/06/2018; Aceito para publicação em 31/10/2018

${ }^{1}$ Universidade Federal do Paraná

${ }^{2}$ Universidade Estadual do Centro-Oeste

*E-mail: carlos.diniz@ufpr.br
} 
meio de ligação entre a extração e o transporte principal, podendo ser realizada de forma manual ou mecanizada, sendo este último o mais utilizado pelas empresas devido à sua elevada eficiência operacional (MINETTE et al., 2002).

Dentre as máquinas mais adequadas para a realização do carregamento florestal, destacam-se os carregadores florestais, que são escavadeiras hidráulicas equipadas com uma garra. A função é realizar a movimentação de toras da pilha de madeira localizada nas margens da estrada ou pátio para o veículo de transporte.

Para Machado (1984), a eficiência operacional das máquinas, o arranjo, o tipo de madeira a ser manuseada, a habilidade e o treinamento do operador podem ser considerados também como fatores de influência no rendimento da operação. Desta forma, o carregamento de madeira deve ser bem planejado e realizado com eficiência, pois influencia diretamente no rendimento e no custo da operação de transporte até a indústria.

A redução no tempo de carregamento e descarregamento proporciona ainda um aumento nas horas efetivas de trabalho dos veículos de transporte e no rendimento pelo maior número de viagens realizadas por dia, aumentando, consequentemente, o volume de madeira transportada por unidade de tempo e reduzindo o custo do transporte da madeira (COSTA et al., 2003).

Neste sentido, o objetivou-se avaliar a influência que os diferentes tipos de sortimento de toras sobre a produtividade da operação de um carregador florestal, visando subsidiar o planejamento e melhor aproveitamento dos recursos disponíveis.

\section{MATERIAIS E MÉTODOS Caracterização da área de estudo}

Os dados para realização do estudo foram obtidos em uma empresa florestal localizada no estado do Paraná, Brasil. O clima da região foi classificado como uma transição entre Cfa e Cfb, subtropical úmido, com temperatura média variando entre $16,3^{\circ} \mathrm{C}$ e $23,2^{\circ} \mathrm{C}$ e precipitação média anual entre 1.478 a $1.700 \mathrm{~mm}$ com altitude média de 750 m (BARBOSA et al., 2007).

A pesquisa foi realizada em povoamentos de Pinus taeda com idade de 17 anos, com volume médio individual de 0,36 a $0,42 \mathrm{~m}^{3}$ sob regime de corte raso e relevo classificado como suave ondulado, de acordo com a Forestry Commission UK (1996).

\section{Caracterização do sistema de colheita}

A colheita de madeira foi realizada por um sistema de colheita de árvores inteiras (full tree) contemplando as máquinas feller buncher, responsável pela derrubada e empilhamento das árvores no interior do talhão. $\mathrm{O}$ arraste das árvores até a beira da estrada foi realizado por um skidder e posteriormente o processamento das árvores foi realizado por um processador harvester.

$\mathrm{Na}$ operação de carregamento da madeira foi utilizado um carregador florestal, composto por uma escavadeira de acionamento hidráulico equipado com uma garra. A jornada de trabalho na empresa é distribuída em dois turnos de doze horas sendo composta por oito frentes de trabalho.

\section{Descrição da máquina estudada}

O carregador florestal estudado é composto por uma escavadeira de acionamento hidráulico de esteiras, marca Caterpillar modelo 320D, equipada com um motor C7.1 Cat ${ }^{\circledR}$ que atende às normas de emissão de Tier 2 da EPA dos EUA. A máquina apresenta ainda potência nominal de $139 \mathrm{HP}$, peso operacional de 23,5 toneladas, lança com alcance de 5,7 metros e uma garra com área útil de $1 \mathrm{~m}^{2}$, (Figura 1).

\section{Coleta de dados}

Os dados foram obtidos nas operações de carregamento de toras de pinus em veículos de carga articulados tipo bitrem, com capacidade de carga bruta de 57 toneladas sendo que o carregamento das toras no veículo foi realizado no sentido longitudinal.

As toras foram classificadas em 4 sortimentos conforme o seu comprimento (TABELA 1). Após o carregamento, as toras foram transportadas para as indústrias para o processamento final da madeira.

Como pode ser observado na Tabela 1, no tratamento IV, as toras foram carregadas de forma a combinar dois tipos de sortimentos, sendo carregado em uma das composições as toras com sortimento de 7,3 metros enquanto na outra foi carregado o sortimento com 3,6 metros. Já nos tratamentos I, II e III as toras foram carregadas sem a combinação de outro tipo de sortimento.

\section{Análise técnica}

Para compor o banco de dados foram coletados dados referente ao número de garradas (quantidade de movimentos necessários para completar a carga), tempo de carregamento e produtividade do carregador florestal para cada sortimento.

A análise técnica do carregador florestal foi realizada por meio de um estudo de tempos e movimentos a partir do método de tempos contínuos, ou seja, sem a paralização do cronometro. 
Foram analisados os elementos do ciclo operacional, que foram subdivididos em: busca de toras, carregamento e deslocamento, sendo consíderadas ainda as interrupções operacionais e não operacionais da atividade. Por fim, foram calculadas a produtividade e a eficiência operacional da atividade.

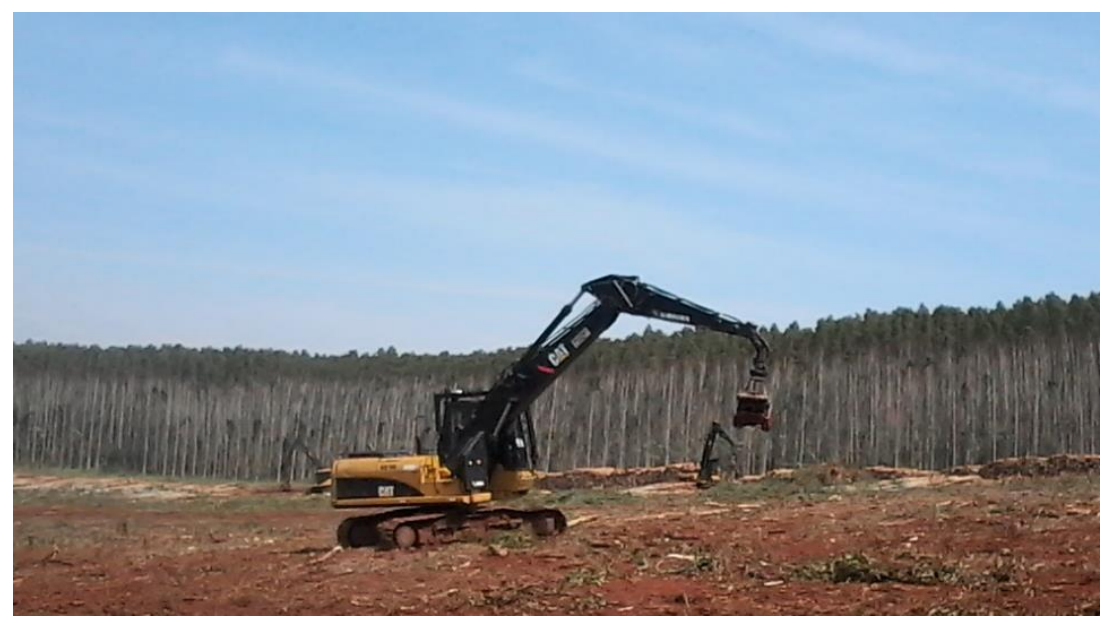

Figura 1 - Carregador florestal Caterpillar 320D.

Tabela 1. Descrição dos sortimentos estudados na operação de carregamento florestal.

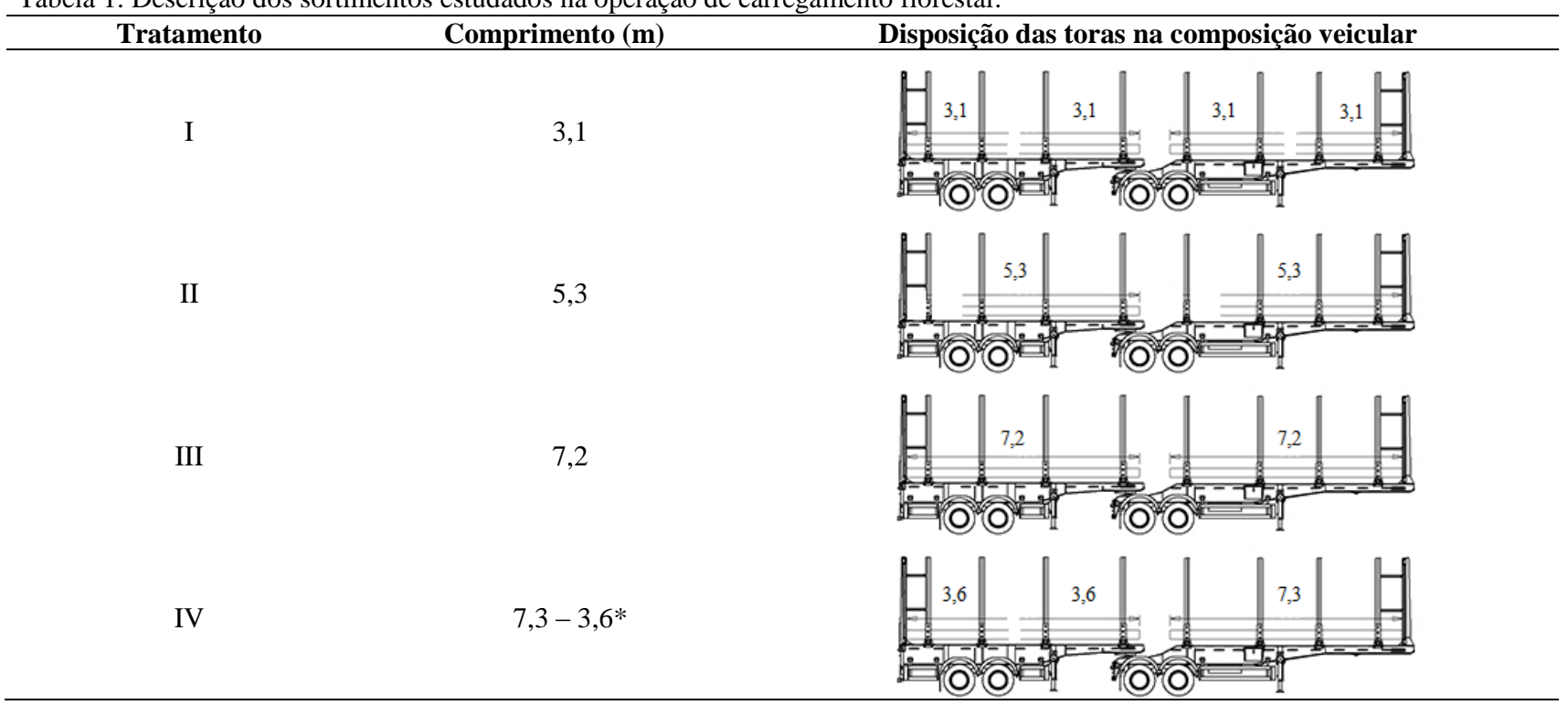

*Sortimento misto.

\section{Estudo de tempos e movimentos}

Inicialmente foi realizado um estudo piloto onde foram definidos o número mínimo de cargas para cada tratamento, proporcionando um erro de amostragem máximo de $5 \%$, de acordo com metodologia utilizada por Simões et al. (2014) e Pereira et al. (2015).

Foi utilizado o método de tempos contínuos, onde o ciclo operacional do carregamento foi subdividido nas seguintes atividades parciais: Busca de Toras (BT); Carregamento (CR), Deslocamento (DE) e Interrupções (INT), sendo essas classificadas em operacionais e não operacionais. As interrupções operacionais compreenderam todas as paradas que tiveram relação com a operação propriamente dita, como por exemplo a realização de uma manutenção corretiva. Já as interrupções não operacionais referiram-se a interrupções que não se relacionam a operação, como a realização de refeições ou outras necessidades básicas. No estudo foi utilizado cronômetro centesimal, prancheta e formulários específicos.

\section{Cálculo da eficiência operacional}

A eficiência operacional, definida como a percentagem do tempo efetivamente trabalhado em relação ao tempo total programado para o trabalho foi obtida por meio da Equação 1. 


$$
\mathrm{EO}=\frac{\mathrm{TT}-\mathrm{INT}}{\mathrm{TT}} \times 100 \quad \text { (Equação 1) }
$$

em que: EO: eficiência operacional (\%); TT: tempo de trabalho (horas); e INT: tempo de interrupções operacionais e não operacionais (horas).

\section{Cálculo da produtividade}

A produtividade média do carregador florestal foi dada em toneladas por hora efetiva de trabalho por meio da Equação 2.

$$
\mathrm{PR}=\frac{\mathrm{PC}}{\mathrm{TC}} \quad(\text { Equação } 2)
$$

em que: PR: produtividade (t. $\left.\mathrm{h}^{-1}\right)$; PC: peso da carga (toneladas); e TC: tempo de carregamento (horas).

\section{Análise estatística}

Foram calculados os valores médios do número de garradas, tempo de carregamento e produtividade do carregador florestal para cada tratamento (I, II, III, IV), posteriormente, feita uma análise $\mathrm{e}$ comparação estatística por meio da análise de variância (ANOVA). Após constatado haver diferença estatística ao nível de 5\% de significância pela ANOVA, realizou-se o teste de Tukey mantendo-se o mesmo nível de significância com a finalidade de avaliar o efeito do sortimento no número de garrada, tempo de carregamento e na produtividade do carregador florestal.

\section{RESULTADOS E DISCUSSÕES}

Foram coletadas 132 cargas realizadas pelo carregador florestal estudado, sendo que os tratamentos I e II contaram com 33 cargas. Já os tratamentos III e IV contaram com 31 e 35 cargas respectivamente. Tal amostragem foi superior ao número mínimo exigido de 30 cargas por tratamento consíderando um erro de $5 \%$.

É possível verificar na Tabela 2 os valores médios de tempo de carregamento para os diferentes tratamentos estudados, bem como valores mínimos, máximos e desvio padrão.

Tabela 2. Tempo médio de carregamento dos tratamentos estudados.

\begin{tabular}{ccccc}
\hline Tratamento & Média & Máximo & Mínimo & Desvpad \\
\hline I & 0,29 & 0,32 & 0,24 & 0,03 \\
II & 0,20 & 0,34 & 0,15 & 0,04 \\
III & 0,24 & 0,29 & 0,17 & 0,05 \\
IV & 031 & 0,36 & 0,26 & 0,01 \\
\hline
\end{tabular}

Como pode ser observado, o tratamento que apresentou menor tempo de carregamento foi o II, seguido dos tratamentos III, I e IV. Esse comportamento pode ser justificado pelo fato das toras presentes no tratamento II possuirem menor comprimento e peso, sendo possível completar a carga em menor tempo que no tratamento III. O tratamento que apresentou menor desvio padrão foi o IV, devido aos resultados obtidos estarem distribuidos de forma homogênea em torno da média.

Na Figura 2 é possível analisar a distribuição dos elementos do cilo operacional junto com as interrupções bem como a eficiência operacional, que foi de $59,7 \%$. Contudo, tal resultado foi obtido sem consíderar os tratamentos, ou seja, foram analizadas as 132 cargas e suas respctivas interrupções operacionais e não operacionais.

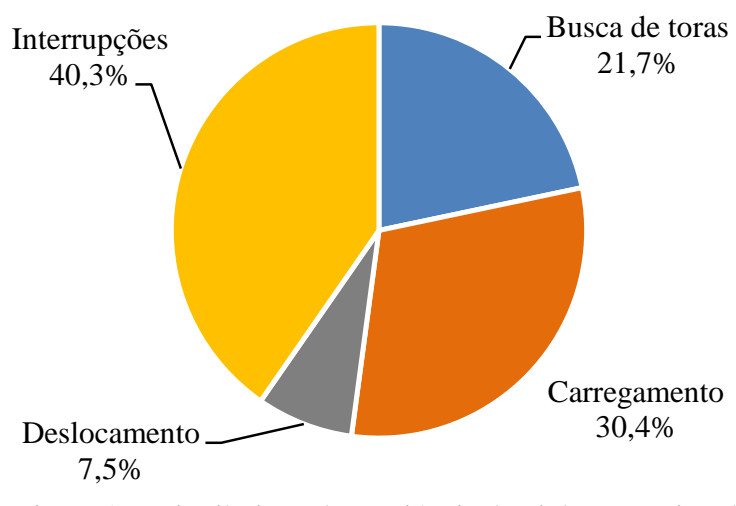

Figura 2 - Distribuição das variáveis do ciclo operacional

Como pode ser observado, a atividade parcial "carregamento" demandou o maior tempo percentual do ciclo operacional com 30,4\%. Tal resultado é similar ao obtido por Lopes et al. (2006) e Dos
Santos et al. (2009) estudando a operação de carregamento florestal. O maior percentual da atividade parcial "carregamento" é explicado pela natureza da própria operação, em que o operador da 
máquina necessita ajustar as toras a serem carregadas de forma com que as mesmas fiquem bem dispostas otimizando espaço no veículo de transporte e reduzindo o risco de acidentes.

É importante ressaltar o elevado tempo consumido pela atividade de "busca de toras" com valor médio de $21,7 \%$. Tal resultado pode ser explicado pela má organização do estaleiro realizada pelo processador harvester na atividade que antecedeu o carregamento.

Quanto as interrupções, principais responsáveis pela baixa eficiência operacional, as paradas que juntas representaram $84,6 \%$ foram aguardando caminhão para carregamento com 46,9\%; deslocamento em pranchancom 10,5\%; aguardando prancha com 9,6\%; preenchimento de nota com 9,5\%; e deslocamento entre talhões com 8,2\%. As demais interrupções são referêntes a pequenas paradas como check list, abastecimento e carregamento da máquina na prancha.
A explicação para o elevado percentual da variável aguardando caminhão para carregamento, está ligada principalmente ao tipo de madeira que a fábrica necessita, desta forma, alguns sortimentos de menor comprimento por vezes tem menor demanda em relação aos sortimentos de maior comprimento, que geralmente são destinados para fabricação de celulose. Outro fator é quando uma frente de trabalho possui duas carregadoras (fato que ocorreu neste estudo), chegando apenas um veículo para o carregamento, de modo que o mesmo seja carregado pela primeira máquina, trancando passagem para que o segundo veículo seja carregado.

Na Figura 3 é possível visualizar o número médio de garradas para cada tratamento estudado. Com base nos resultados do teste de Tukey $\left(\mathrm{p}_{\text {valor }}<0,05\right)$, verifica-se que as diferentes dimensões dos sortimentos influenciam de forma significativa no número de garradas.

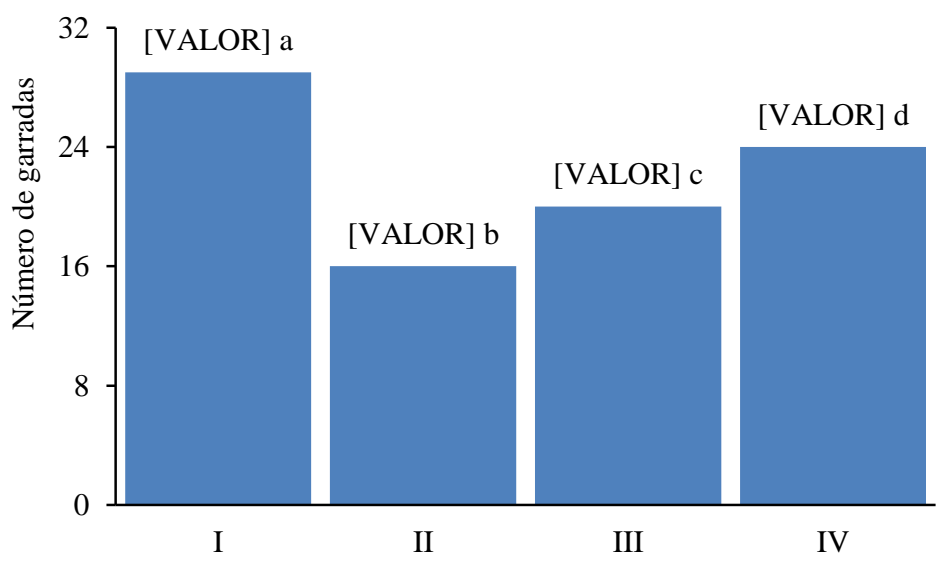

Médias seguidas das mesmas letras não diferem pelo teste de Tukey ( $\left.\mathrm{p}_{\text {valor }}<0,05\right)$.

Figura 3 - Médias do número de garradas para cada tratamento estudado.

Os tratamentos que demandaram menor número de garradas para completar a carga foram II e III seguidos dos tratamentos IV e I respectivamente. Verificando a Tabela 1, onde é possível observar a disposição das toras na composição veícular, podese ter maior clareza da explicação de tais resultados. No tratamento I por exemplo, o operador da máquina têm de carregar duas vezes a mesma composição veícular, logo, precisa realizar mais movimentos com a grua.

Outro ponto que chama atenção é o resultado obtido para o tratamento III, que apresenta aumento significativo em relação ao II. Tal resultado é ligado ao peso das toras encontradas no sortimento III, que por apresentarem maior comprimento, se tornam mais pesadas, assim, para ter melhor dominio dos movimentos e operar com segurança, sem danificar a máquina por forçar movimentos, o operador necessitava pegar um número menor de toras por garrada, gerando aumento no número médio de garradas por carga.

Em relação a produtividade e tempo de carregamento, percebe-se que os tratamentos II e III foram os que apresentaram os melhores resultados (FIGURA 4). É importante destacar ainda que em ambas as váriaveis foi possível detectar diferença estatística pelo teste de Tukey $\left(\mathrm{p}_{\text {valor }}<0,05\right)$. 


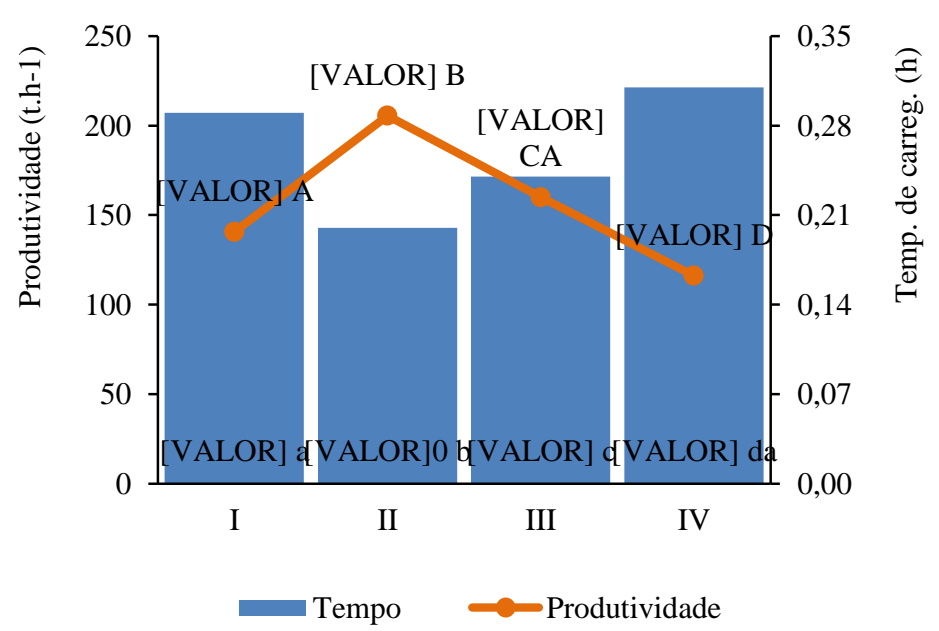

Médias seguidas das mesmas letras maiúsculas e minúsculas não diferem para as variáveis produtividade e tempo de carregamento, respectivamente, pelo teste de Tukey $\left(\mathrm{p}_{\text {valor }}<0,05\right)$.

Figura 4 - Produtividade e tempo do ciclo operacional para os tratamentos estudados.

De acordo com os resultados, fica evidente que os tratamentos II e III se destacam em relação aos demais, obtento um ganho de até $43 \%$ de produtividade em relação ao tratamento IV, que apresentou os piores resultados para as variáveis produtividade e tempo do ciclo operacional.

Se adotarmos a mesma linha de raciocínio do número de garradas, o tratamento IV deveria apresentar resultados superioes aos do tratamento I, haja visto que a carga do tratamento IV possui dois tipos de sortimentos. Contudo, a redução da produtividade e do tempo do ciclo operacional foram influênciados pela disposição dos sortimentos no campo, onde os mesmos não se encontravam no mesmo local, fazendo com que a máquina e o veículo de transporte se deslocasem para completar a carga, elevando o tempo do ciclo operacional, reduzindo assim a produtividade da máquina.

Como já mencionado anteriormente, para os resultados dos tratamentos II e III, pode-se aplicar a mesma explicação do número de garradas, onde para o sortimento II, com toras de menor comprimento e mais leves, foi possível completar a carga com menor número de garradas, implicando em menor consumo de tempo para operação, elevando assim a produtividade da mesma.

Dos Santos et al. (2009) avaliando técnicamente a operação de um carregador florestal com diferentes sortimentos de madeira obtiveram produtividade semelhante para sortimentos de 3,6 m, sendo neste estudo o tratamento I, com $140,6 \mathrm{t.}^{\mathrm{h}-1}$ o valor mais próximo. A maior produtividade foi identificada no sortimento II com 205,6 t. ${ }^{\text {h-1 }}$, seguido dos tratamentos III, I e IV.

\section{CONCLUSÕES}

$\mathrm{O}$ tipo de sortimento influênciou na produtividade do carregador florestal, sendo a maior produtividade encontrada no tratamento II, seguido pelo tratamento III.

Os menores tempos de carregamento foram obtidos nos tratamentos II e III, que apresentaram as maiores dimensões de comprimento, onde em cada composição do veículo de transporte era carregado apenas uma vez.

$\mathrm{O}$ tratamento I foi o que apresentou maior número de garradas devido ao menor comprimento das toras, pois era necessário carregar quatro vezes as combinações veículares do veículo de transporte.

Para o aumento da eficiência operacional do carregador florestal, tornam-se necessárias melhorias no sistema de logística, principalmente no que se refere a distribuição dos veículos de transporte.

\section{REFERÊNCIAS}

ARCE, J. E., MACDONAGH, P., FRIEDL, R. A. Geração de padrões ótimos de corte através de algoritmos de traçamento apli- cados a fiastes individuais. Revista Árvore, v.28, n.2, p.383-391, 2004.

BARbosa, C. E., BENATO, A. T., CAVAlHEIRO, A. L., TOREZAN, J. M. D. Diversity of Regenerating Plants in Reforestations with Araucaria angustifolia (Bertol.) O. Kuntze of 12, 22, 35, and 43 Years of Age in Parana State, Brazil. Restoration Ecology, Malden, v. 17, n. 1, p. 60-67, 2007.

COSTA, F. A., SOUSA, R. A. T. M., LEITE, A. M. P. Transporte rodoviário de madeira: um estudo de caso na Amazônia. In: SIMPÓSIO BRASILEIRO SOBRE COLHEITA E TRANSPORTE FLORESTAL, 6., 2003, Belo Horizonte. Anais. Belo Horizonte: UFV/SIF, 2003. p.349-363.

DOS SANTOS, M. D., LOPES, E. S., DIAS, A. N., RIBEIRO, A. B. Avaliação técnica de um carregador florestal com diferentes sortimentos de madeira. Revista Ambiência, Guarapuava, v. 5, n. 1, p. 13-26, 2009. 


\section{FORESTRY COMMISSION UK. 1996. Terrain}

Classification. Disponível em:

<http://www.biomassenergycentre.org.uk>. Acesso em: 01 de mai. 2018.

LOPES, E. S., CRISTO, J. F. C., PIEPER, M. Avaliação técnica de um sistema de pesagem no carregamento florestal. Revista Árvore, Viçosa, v. 30, n. 4, p. 575-581, 2006.

MACHADO, C. C. Planejamento e controle de custos na exploração florestal. Viçosa: UFV, $1^{\mathrm{a}}$ ed., Impr. Univ., 1984, 138p.

MACHADO, C. C. Colheita Florestal. Viçosa: UFV. $3^{\mathrm{a}}$ ed., Imp. Univ., 2014. 468p.

MiNeTTI, L. J., SOUZA, A. P., FIEDLER, N. C. Carregamento e descarregamento. In: Colheita Florestal / Carlos Cardoso Machado (Org.). Viçosa: UFV, v.1, p. 129-144, 2002.
NASCIMENTO, A. C., LEITE, A. M. P., SOARES, T. S., FREITAS, L. C. Avaliação técnica e econômica da colheita florestal com feller buncher. Revista Cerne, Lavras, v. 17, n. 1, p. 9-15, 2011.

PEREIRA, A. L. N., LOPES, E. S., DIAS, A. N. Análise técnica e de custo do Feller-buncher e Skidder na colheita de Madeira em diferentes produtividades do povoamento. Revista Ciência Florestal, Santa Maria, v. 25, n. 4, p. 981-989, 2015.

SIMÕES, D., FENNER, P. T., ESPERANCINI, M. S. T. Produtividade e custos do feller buncher e Processador Florestal em povoamentos de eucalipto de primeiro corte. Revista Ciência Florestal, Santa Maria, v. 24, n. 3, p. 621- 630, jul./set. 2014 